\title{
An Investigation Report on the Learning Interests of Foreign Students in Chinese Culture-A Case of North China University of Technology
}

\author{
Wei WU, Ling-wei YIN \\ North China University of Technology, Beijing, China
}

\begin{abstract}
As more and more students want to know Chinese culture, the teaching of Chinese culture has become an important part of teaching Chinese as a foreign language. And "what to teach" and "how to teach" in the teaching practice of Chinese culture have become urgent problems to be solved. Through the questionnaire survey of our students, we find the topics that the students are interested in, know the preference of the students in the theory and practice of culture teaching, and provide a strong reference for the future design of teaching.
\end{abstract}

Keywords: foreign students, culture, teaching, practice, questionnaires

\section{Introduction}

With the worldwide study of Chinese learning booming, more and more foreign students choose to study in China. International students come to China, not only to learn Chinese, to understand Chinese culture is also a lot of students' purposes. In this way, the teaching of Chinese culture has become an emerging and important part of teaching Chinese as a foreign language. LI Jia-yu (2002) has proposed that "cultural education in Chinese education has dual tasks: One is cultural factors teaching subordinate to language teaching, and the other is independent national culture education". In recent years, the scale of the foreign students has expanded rapidly in our school. By the beginning of 2015, 373 students from 45 countries have studied in our school, of which 240 have received academic education. At present, our school for different major undergraduate students has opened a Chinese culture class, then "what to teach" and "how to teach" in the classroom are the main problems, which need to be carefully considered; and at the same time, cultural practice is an indispensable part of the cultural and educational content. In this environment, in order to know some of the views of our students on the practice of Chinese culture teaching, I designed a number of questions to do a survey so that we can clearly judge the thoughts of the students, which can improve the future teaching practice of Chinese culture education.

\section{Questionnaire}

The questions of the research involve students' interest in different aspects of Chinese culture, such as whether they are interested in Chinese culture, whether it is necessary to know Chinese culture, and whether

Wei WU, lecturer, M.A., Department of Teaching Chinese as a Foreign Language, North China University of Technology \& PhD Student, Beijing Language and Culture University.

Ling-wei YIN, lecturer, M.A., Department of Teaching Chinese as a Foreign Language, North China University of Technology. 
there is any interest in folklore, educational science \& technology, literature $\&$ art, tourism, and other cultures. They are also related to the students to set up Chinese culture curriculum time preferences survey; learning Chinese culture; learning Chinese culture reasons; learning Chinese culture curriculum theory and practice ratio and so on.

The questionnaire designed 25 questions, a total of three parts. The first part is to find out the basic situation of foreign students; the second part, also the main part, is to investigate the interests of students in different contents of Chinese culture; the third part is to investigate the students' views on the course of teaching time and the teaching way and to provide the students with the supplement part.

Questionnaires were sent to language and academic students, the final total of 120 valid questionnaires.

\section{Survey Results}

According to statistics, the proportion of boys and girls in the survey is $37.5 \%$ and $60.83 \%$, which basically meets the requirements of the proportion of male and female in the survey. Most of the age groups are concentrated on the age of 19-22 and 23-25. Foreign students are from different countries, which the majorities are from South Korea, Japan, Cameroon, Turkmenistan, Congo, and the largest number is Korean students. Fifty-three of the respondents were language students and 65 were academic students. About the survey of students' major, because the language students do not choose any major, they do not participate in the proportion of major of statistics; therefore, among the respondents in the top three major are the international economy and trade, Chinese language and literature, and management. Nearly half of the surveyed students have received high school education, which can be seen that many students came to our school to study academic education. The time of students who came to China varies from zero to six months. Most students learn Chinese less than one year and for 1-3 years. The majority of their Chinese proficiency is normal. Whether or not the students had previously attended the cultural class had a small proportion. These are the statistics of the basic situation of the respondents, so that it is more convenient in the future survey.

The following is simple statistics on the interest of Chinese students in Chinese culture, including 19 questions, each answer of the question is divided into four levels: complete agreement, basic agreement, cannot tell, and disagreement.

The data shows that $87 \%$ of the students are fully or basically agreed to be interested in Chinese culture, which means that most of the students like Chinese culture. Almost half of the students know Chinese culture well, which shows that students usually pay more attention to Chinese culture. There is an urgent need for foreign students to know the needs of Chinese culture, which is also the effective implementation of the practice of Chinese culture and education to provide a strong support. Most students think that it is beneficial to know Chinese culture for learning Chinese language. This proves "culture can help students better understand Chinese" (LI, 2012, p. 19). Language and culture are inseparable. Language can help students know the culture better and understanding the cultural knowledge has played a role in promoting language learning. International students think that if they know some culture, it is very helpful in dealing with the Chinese people. In fact, in real life, students will encounter a very embarrassing situation which is that they found that some of the Chinese people's words during the communication are not the same with the ones students themselves in the classroom learned. The reason of this situation is that Chinese people in the communication will often mix with some Chinese culture in it, so during this time if students do not understand the meaning of Chinese culture, they will not understand what Chinese people are talking. Students in the love of Chinese literature, "basic 
agreement" and "cannot tell" occupy most of the proportion of which girls like to learn Chinese literature than boys. In other words, Chinese literature is not the favorite of most students, which provides the basis for teachers to prepare lessons and reference. Nearly half of the students totally agree that traditional Chinese festivals are the most interesting festivals. About $40 \%$ of the students in the religious philosophy of Chinese culture hold "cannot tell" attitude and another $40 \%$ of students hold "basic agreement" attitude. This may be related to the environment in which students are exposed, because there is little talk about religious issues in the daily lives of Chinese people. Most of the students think that Chinese architecture is the most attractive Chinese culture. $46 \%$ of the students on the food culture hold "basic agreement" attitude and $29 \%$ of the students choose "cannot tell", which can explain the interest of students in the food culture is not particularly high, but in general. Most of the students like Chinese art and culture, such as calligraphy, opera and so on. So in the future, the teaching design can be added some of this content. Nearly half of the students think that traditional Chinese craft is the most attractive Chinese culture. Nearly $80 \%$ of international students believe that traditional Chinese clothing is their favorite culture, so cultural practice can be designed in the future in order for students to be able to access to ancient clothing so that theory and practice can strengthen students' aesthetics of Chinese costumes. The interest of Chinese students in Chinese science and technology culture holds the attitude of "cannot tell" and "basic agreement". This result provides a reference for the content of Chinese culture teaching. The attitude of foreign students to the Chinese sports is that $41 \%$ of the attitude of foreign students is the "basic agreement", followed by "cannot tell", and the results show that China's sports culture is not very attractive for students, which provides a reference for future screening of course content. On the theme of education development in China, 38\% of the students have a "basic agreement" attitude and holding "cannot tell" and "fully agreement" attitude of the proportion of students is not much different, indicating that students' interest in educational development is not very high. Fifty-five percent of the students choose "fully agree" about China's tourism culture which is the most attractive culture to them and $27.5 \%$ of the students choose "basic agreement", from which we can see that students are very interested in China's tourism culture. Because of this kind of data, some of this knowledge can be added in the future teaching practice curriculum design to meet the students' appetite. Most students want to learn more about Chinese culture. The students who choose "fully agree" are willing to understand more Chinese cultural knowledge, therefore, in the future of foreign students education, it is important to be tangible and intangible infiltration of Chinese culture knowledge, not just some knowledge of Chinese culture learned in the class. In addition, language classes should be also appropriate to set up Chinese culture classes or different levels of language teaching and penetrate some of the Chinese cultural knowledge so as to meet the needs of students. Most of the students think that their major or career who later want to engage in the occupation for the choice of learning Chinese cultural content will have a great impact.

The above is a simple descriptive statistical analysis of the second part of the questionnaire and the following statistical results are classified as the induction of the second part of the question 1 to question 19 and then find out the relationship between the basic situation of the students and their interest in Chinese culture. The conclusions are:

(1) The gender (male and female) on education, science and technology culture and tourism, and sports culture has some different impact, but there is no difference in gender to other aspects; 
(2) Student identity (language students, major students) on the interest in Chinese culture and the necessity study of Chinese culture has different impact, but has no effect on other aspects;

(3) Whether students have taken the cultural class (yes, no) has a different interest in Chinese culture learning, but has no effect on other aspects;

(4) The differences in age, major, education and the time to study Chinese have nothing to do with the interest in Chinese culture learning and the perception of cultural necessity and the interest in the culture of literature and art, the folk culture, the educational science and technology culture, and tourism culture.

(5) The differences of the time to stay in China have no effect on the interest of Chinese culture learning and the need to know Chinese culture, education, science and technology culture, and tourism and folk culture. However, as the data obtained from $0.046<0.05,0.046<0.05$ is significant. The time for students to be in China: 0-6 months and 6-12 months have significant differences in the impact of literary and artistic culture. $1.000>0.05,1.000>0.05$, so the time for the students to be in China in the 1-2 years and more than two years has no differences in the impact of literary and culture;

Table 1

Variance Homogeneity Test

\begin{tabular}{llll}
\hline \multicolumn{2}{l}{ Mean of literary and artistic culture } & & \\
\hline Levene statistics & $\mathrm{df1}$ & $\mathrm{df2}$ & Sig. \\
\hline 2.498 & 3 & 112 & .063 \\
\hline
\end{tabular}

Table 2

ANOVA

\begin{tabular}{llllll}
\hline \multicolumn{7}{l}{ Mean of literary and artistic culture } \\
\hline & Sum of squares & df & Mean square & F & Sig. \\
\hline Between groups & 3.698 & 3 & 1.233 & 2.695 & .049 \\
\hline
\end{tabular}

Table 3

Multiple Comparisons

Dependent variable: Mean of literary and artistic culture

\begin{tabular}{|c|c|c|c|c|c|}
\hline & $\begin{array}{l}\text { (I) time in China } \\
\text { (Question 7) }\end{array}$ & $\begin{array}{l}\text { (J) time in China } \\
\text { (Question 7) }\end{array}$ & Mean difference (I-J) & Std. error & Sig. \\
\hline \multirow{12}{*}{ Bonferroni method } & \multirow[t]{3}{*}{ 2A. 0-6 months } & 3B. 6-12 months & .50263 & .18503 & .046 \\
\hline & & 4C. $1-2$ years & .10385 & .16660 & 1.000 \\
\hline & & 5D. over 2 years & .01731 & .16660 & 1.000 \\
\hline & \multirow[t]{3}{*}{ 3B. 6-12 months } & 2A. $0-6$ months & -.50263 & .18503 & .046 \\
\hline & & 4C. $1-2$ years & -.39879 & .20412 & .319 \\
\hline & & 5D. over 2 years & -.48532 & .20412 & .115 \\
\hline & \multirow{3}{*}{ 4C. 1-2 years } & 2A. $0-6$ months & -.10385 & .16660 & 1.000 \\
\hline & & 3B. 6-12 months & .39879 & .20412 & .319 \\
\hline & & 5D. over 2 years & -.08654 & .18757 & 1.000 \\
\hline & \multirow[t]{3}{*}{ 5D. over 2 years } & 2A. $0-6$ months & -.01731 & .16660 & 1.000 \\
\hline & & 3B. 6-12 months & .48532 & .20412 & .115 \\
\hline & & 4C. $1-2$ years & .08654 & .18757 & 1.000 \\
\hline
\end{tabular}

(6) Different Chinese level has no effect on the interest of Chinese culture learning and the need to know Chinese culture, literature and art culture, education, science and technology culture, and folk culture. But because of the data from the $0.045<0.05,0.045<0.05$ and $0.025<0.05$ are significant, there are significant differences on the cultural interest of the impact of tourism culture among the Chinese level—very good, good, 
and generally. $0.763>0.05$ is not significant, so there is no significant difference on the impact of Chinese language level on the impact of sports culture (see Table 4-Table 6).

Table 4

Variance Homogeneity Test

\begin{tabular}{llll}
\hline Mean of travelling and sports culture & & \\
\hline Levene statistics & df1 & df2 & Sig. \\
\hline .796 & 3 & 111 & .499 \\
\hline
\end{tabular}

Table 5

ANOVA

\begin{tabular}{llllll}
\hline \multicolumn{2}{l}{ Mean of travelling and sports culture } \\
\hline & Sum of squares & df & Mean square & F & Sig. \\
\hline Between groups & 6.234 & 3 & 2.078 & 3.546 & .017 \\
\hline
\end{tabular}

Table 6

Multiple Comparisons

\begin{tabular}{llllll}
\hline Dependent variable: Mean of travelling and sports culture & & & \\
\hline & $\begin{array}{l}\text { (I) Chinese level } \\
\text { (Question 9) }\end{array}$ & $\begin{array}{l}\text { (J) Chinese level } \\
\text { (Question 9) }\end{array}$ & Mean difference (I-J) Std. error & Sig. \\
\hline & 2A. very good & 3B. good & -.78105 & .28697 & .045 \\
& & 4C. general & -.80876 & .27638 & .025 \\
& 5D. poor & -.47222 & .30727 & .763 \\
3B. good & 2A. very good & .78105 & .28697 & .045 \\
& & 4C. general & -.02771 & .16884 & 1.000 \\
& 5D. poor & .30882 & .21572 & .930 \\
& 4C. general & 2A very good & .80876 & .27638 & .025 \\
& 3B. good & .02771 & .16884 & 1.000 \\
& 5D. poor & 5D. poor & .33654 & .20142 & .585 \\
& & 2A. very good & .47222 & .30727 & .763 \\
\end{tabular}

The above findings show that those influencing factors should be focused on the future teaching content, which provides a strong evidence for the scientific design of teaching.

The third part of the questionnaire draws the following conclusions: Most students think that it is the most appropriate to open Chinese culture courses in the primary stage and intermediate stage. The way students understand Chinese culture is also mainly through the teacher's explanation and with some Chinese students' communication to better understand Chinese culture. Most of the students study Chinese culture not only because of the need for future work, but also the interest in Chinese culture, besides these, some students think it is helpful to travel in China. About the question of the teaching design of theory and practice of Chinese culture, the order of the result is as follows: First, the 50\% theory and 50\% practice teaching design is very popular with students, followed by the $100 \%$ practice of the design, then the theory of $70 \%$ plus practice of $30 \%$ teaching design. In the part of the students' free expression, some students want to know the food culture and then a small number of students want to know the history of China and the history of all the emperor's story, there are also a couple of students want to know the traditional dance, Chinese families, China economy, the history of China's economy, Chinese business culture, and other knowledge.

Language and culture are interdependent and inseparable. "Language teaching is bound to involve a certain cultural content, and also must include a certain cultural factors, but the teaching of cultural factors must 
be language teaching services" (LIU, 2014, p. 19). It is very important to determine the cultural content in the teaching of Chinese as a foreign language. Through the above results, we can provide some information for the design of the teaching content of Chinese culture in the future. Only after taking full account of the students' willingness to design the teaching content which can meet the teaching requirements and make the students interested in the course can the course be knowledgeable and interesting.

\section{Conclusion}

In Chinese teaching, cultural teaching is generally divided into two categories: One is the language teaching in language classes, that is, to penetrate cultural awareness in language teaching, which is a hidden cultural teaching; the other is a special cultural class teaching, including cultural practice, which is called explicit cultural teaching. (LI, 2015, p. 8)

At present, the teaching subject of Chinese culture is mainly academic class, that is, specialized culture teaching. Cultural teaching includes classroom teaching and cultural practice. "Classroom teaching is the basis and focus of cultural teaching research" (LI, 2015, p. 12), the survey highlights the "interest of students as the fundamental starting point" to help better understand the needs of students, and the curriculum design guided by students' needs is to provide the basis for the theoretical teaching and practical experience of Chinese culture courses offered for undergraduates of our specialties, which helps teachers to add some reference in order to prepare lessons to solve the main problems of "what to teach" and "how to teach". "Cultural practice as an important part of cultural teaching has attracted a lot of attention and discussion" (LI, 2015, p. 13). This investigation also contains the practice part of the relevant issues, which can make cultural lessons interesting and can also design some practice in accordance with the preferences of students to help students better understand the connotation of Chinese culture teaching and practice education in the future so that students really understand the true meaning of Chinese culture. The survey reflects the fact that some of the contents of the Chinese culture curriculum are rigid and boring or that students cannot come into contact with the actual life, so students feel boring, which inspires teachers to try to grasp the balance of content coverage in the future curriculum content design, but also try to take care of the interests of most students, try to design some students interested, and not deviate from the contents of Chinese culture to explain, I believe there will be more and more students love Chinese culture. In the theoretical teaching at the same time, practical teaching is also very important. Theory and practice are complementary; theory is the practice of guidance and practice is the support of the theory. Chinese cultural theory teaching can help students understand China's profound cultural knowledge and Chinese cultural practice can provide students with a chance to experience the culture to help students deepen their impression, better understand, and digest the knowledge learned, but also can enhance the students' self-confidence and sense of accomplishment. The survey is limited by the time and other conditions, the scope is small, and the number is small; the questionnaire content also needs to improve, for example, multiple choice of the score design should be changed to the fractional value system, of course, we cannot fully base on this survey to design the curriculum, but at least as a reference to the teaching design. In the future investigation and research, we will continue to improve the design of such questionnaires to improve the reliability of the questionnaire survey for the Chinese culture and education teaching practice content and methods to provide a more effective basis. 


\section{References}

LI, H. Y. (2015). Chinese culture teaching research. Shanghai: The Commercial Press.

LI, J. Y. (2002). On the Chinese culture in the understanding of cultural issues. Overseas Chinese Education, $22,72$.

LI, X. Q. (2012). Teaching Chinese as a foreign language. Shanghai: The Commercial Press.

LIU, X. (2014). Introduction to teaching Chinese as a foreign language. Beijing: Beijing Language University Press. 